\title{
The Changes in Medication Prescribing Among the Older People with Cognitive Impairment in the Acute Care Setting
}

This article was published in the following Dove Press journal:

Clinical Interventions in Aging

\author{
Sirasa Ruangritchankul (D) ${ }^{1,2}$ \\ Nancye M Peel (D') \\ Leila Shafiee Hanjani (D) \\ Leonard C Gray (D)
}

'Centre for Health Services Research, Faculty of Medicine, The University of Queensland, Brisbane, QLD, Australia;

${ }^{2}$ Division of Geriatric Medicine, Department of Medicine, Faculty of Medicine, Ramathibodi Hospital, Mahidol University, Bangkok, Thailand
Correspondence: Sirasa Ruangritchankul Division of Geriatric Medicine, Department of Medicine, Faculty of Medicine, Ramathibodi Hospital, Mahidol University, 270 Rama VI Road, Ratchathewi, Bangkok 10400, Thailand Tel +66816404373

Fax +6622012588

Email sirasarama37@gmail.com
Purpose: Most older people with cognitive impairment usually have multiple comorbidities. In the last decade, the guidelines for the management of chronic diseases have been changed, leading to changes in the patterns of medication prescribing and in the prevalence of drugrelated problems (DRPs). The main objectives were to explore the changes in medication use and in the prevalence of polypharmacy (PP), the use of potentially inappropriate medications (PIMs) and drug-drug interactions (DDIs) among older hospitalized adults with cognitive impairment in a 5-year period.

Patients and Methods: Older hospitalized patients with cognitive impairment diagnosed by cognitive performance scale (CPS) score of 2 or more at tertiary hospital in Brisbane, Australia in 2009 and 2015 to 2016 were enrolled. Prescribed medication use, and exposures to PP, PIM and/ or DDI were evaluated at two time points. The associated factors with patients exposed to $>1$ criteria of PP, PIM or DDI were analyzed by using logistic regression analyses.

Results: The median number of prescribed medications was not significantly different between the two periods. The number of medications use as dermatological agents and analgesics substantially increased over 5 years. In contrast, there was a decrease in prescription of drugs for acid-related disorders, drugs used in diabetes, and mineral supplements. Most of the participants were exposed to at least one of PP, PIM or DDI. In multivariate regression analysis, the presence of diabetes diagnosis was a risk factor associated with increased exposure to $>1$ criteria of PP, PIM or DDI.

Conclusion: The patterns of many prescribed medications use have altered in a 5-year period. The present study confirms that the majority of older adults with cognitive impairment admitted in an acute care setting are prone to PP, PIM and DDI. Comprehensive medication reviews should be undertaken in clinical care of older patients with cognitive impairment.

Keywords: older adults, cognitive decline, hospitalization, polypharmacy, potentially inappropriate medication, drug-drug interaction

\section{Introduction}

The increase in global population aging is as a result of a longer life expectancy. ${ }^{1}$ In Australia, the population of older adults aged 65 years and over has been predicted to rise markedly from 3.8 million in 2017 to reach 8.9 million in $2066 .^{2}$ With increased longevity, many older persons need a great deal of medical care and medications. Therefore, hospital admission of older patients has rapidly increased. ${ }^{3}$ In previous studies, $65 \%$ of admitted patients were aged 65 years or older, and they 
accounted for $70 \%$ of bed days. ${ }^{4}$ Factors associated with greater risks of hospitalization are advanced age, cognitive impairment, poor physical performance, multiple comorbidities and presence of potentially inappropriate medications. ${ }^{5-7}$

In acute care settings, approximately $38 \%$ of admitted older adults aged 65 years and over have some form of cognitive impairment. ${ }^{8}$ In many cases, patients have developed cognitive impairment after hospitalization. ${ }^{9}$ Cognitive impairments are often associated with some medical conditions, for example, congestive heart failure (CHF), delirium, undiagnosed dementia and Chronic Obstructive Pulmonary Disease (COPD) ${ }^{10-12}$ Older patients with cognitive impairment admitted in hospitals pose greater risks such as economic burdens and detrimental health outcomes, namely frailty, malnutrition, falls, superimposed delirium and mortality. ${ }^{8,13}$ These unfavorable health consequences result in increased medications consumed for treatment, symptom control, or improving quality of life. In addition, cognitively impaired older patients usually have multiple chronic comorbidities, leading to increasing demands of multiple medication use or polypharmacy (PP). ${ }^{14-16}$ During the period from 2010 to 2015, several evaluation tools were developed and widely used to assess the quality of medication prescribing in older adults, including revised Beers Criteria in 2012 and 2015, ${ }^{17,18}$ STOPP criteria, ${ }^{19}$ and European Union (EU)-PIM list. ${ }^{20}$ In terms of chronic diseases management, medications have been increasingly used as preventive agents to modify and reduce the health risk. ${ }^{21}$ Furthermore, many new medications were developed and introduced to the market such as NOACs (Novel Oral Anticoagulants) and hypoglycemic drugs such as sodium-glucose transport protein 2 (SGLT2) inhibitor. ${ }^{22}$ These can result in changes in patterns of medication prescribing and stimulate an increase in medication consumption. ${ }^{23-27}$

It is known that polypharmacy, defined as the concurrent use of five or more regular prescription medications, ${ }^{28}$ increases the risk of undesirable drug-related problems (DRPs), including adverse drug reactions (ADRs), the use of potentially inappropriate medications (PIMs), drug duplication, drug-drug interactions (DDIs) and medication nonadherence. ${ }^{29-31}$ Cognitively impaired older people, compared to those without cognitive impairment, have an increased susceptibility to DRPs due to changes in neurotransmitter substances, and alterations in the blood-brain barrier increasing sensitivity to medications. ${ }^{32,33}$ Other factors related to DRPs are age-related changes in the pharmacokinetics and pharmacodynamics of medication. ${ }^{34}$ DRPs have negative impacts on public health and may result in prolonged hospitalization, increased healthcare expenditure burden, morbidity and mortality. ${ }^{35-37}$ These problems have a tendency to occur frequently and are more serious in older patients with cognitive impairment due to their frailty and vulnerability.

A recent study has indicated a high prevalence of PP reported to be $76 \%$ among Australian older patients admitted to an acute care hospital. ${ }^{16}$ In terms of PIMs and DDIs at admission, the prevalence in Australian elderly patients for at least 1 PIM and 1 DDI is $39-60 \%{ }^{38-40}$ and $71 \%{ }^{41}$, respectively. Other studies have revealed the prevalence of PIMs among older hospitalized patients with cognitive impairment ranging from $53 \%$ to $90 \%{ }^{42,43}$

However, in the cognitively impaired older adults admitted in acute care settings, the changes in medication prescribing as well as prevalence and characteristics of PP, PIM and DDI have so far been scarcely studied. The knowledge regarding trends in underlying medications and PP is essential to determine efforts to reduce PIM and DDI. The objective of the current research was to explore changes in the patterns of medication use among hospitalized older adults with cognitive impairment in a 5-year period (in 2009 and 2015 to 2016). Another objective was to investigate prevalence of PP, PIM and DDI, and risk factors associated with the exposure to $>1$ criteria of PP, PIM or DDI.

\section{Patients and Methods Study Design, Setting and Participants}

The present research was a secondary analysis of a crosssectional study of 330 patients aged 65 years or older with cognitive impairment referred for geriatric consultation services at Princess Alexandra Hospital, Brisbane, Australia in 2009 and 2015 to 2016.

\section{Data Collection and Measurement Tools}

In the study, all health information data were provided from the Comprehensive electronic Geriatric Assessment Online database which incorporates the interRAI Acute Care (AC) assessment system as a standard tool used in the acute care setting for older patients who were referred for comprehensive geriatric assessment (CGA). ${ }^{44}$ The interRAI Acute Care (AC) assessment system is a comprehensive assessment system designed for use among older patients who have complex physical, functional and psychological needs. Trained nurse assessors gathered health information in terms of physical, physiological-behavioral and socio-economic status by direct observations as well as interviews with patients, caregivers and staff and medical record reviews. The variables included baseline 
characteristics, activities of daily living (ADL), mood and behavioral patterns, cognitive functions, communication, continence, health conditions, nutritional status, falls, diagnoses and all prescribed medications. ${ }^{44}$ A number of scales, diagnostic and risk screeners embedded in the interRAI instruments served as outcome measures of severity. ${ }^{45}$ The participant's degree of cognitive impairment was evaluated by embedded computer algorithms of InterRAI AC, which interpreted collected clinical data on cognitive function to create a cognitive performance scale or CPS (highly correlated with the MiniMental State Examination) ${ }^{46}$ with scores ranging from 0 (intact) to 6 (severe cognitive impairment). Cognitive impairment was defined as a CPS score of 2 or more. Functional capacity and levels of dependence were evaluated by short ADL scale at admission and premorbid IADLs scale which were also embedded in InterRAI Acute Care (AC) database. ${ }^{47,48}$ The ADL short-form scale comprises four items (personal hygiene, walking, toilet use and eating), ranging from 0 to 16, with higher scores reflecting greater level of dependency. ${ }^{45,47}$ Premorbid IADL scale summarizes the performance on seven IADL items (meal preparation, housework, finances, medication management, phone use, shopping, and transport). The scale has a range from 0 to 42 , with higher scores indicating greater dependence. ${ }^{45,47}$ In terms of medication issues, all prescribed medications (both regular and as required medications) were recorded at the time of assessment. Each patient's medications were categorized using the World Health Organization's Anatomical Therapeutic Chemical (ATC) system. ${ }^{49}$ This system is a drug classification system that is used to classify the active ingredients of drugs according to the organ or system on which they act and their therapeutic and pharmacological properties. Finally, the prevalence and characteristics of PP, PIM and DDI were identified using the following definitions.

\section{Definitions PP}

$\mathrm{PP}$ is simultaneous use of five or more regular prescription medications. ${ }^{28} \mathrm{PP}$ was classified into three groups: 0-4 drugs (non-PP), 5-9 drugs (PP) and $\geq 10$ drugs (excessive$\mathrm{PP})$, based on the number of regular-prescribed medications documented in the interRAI AC database. ${ }^{50}$

\section{PIM}

PIM is defined as the use of medications that should be entirely avoided in the older adults due to more risks than benefits. ${ }^{51}$ PIMs were determined by the 2019 American Geriatrics Society (AGS) Beers Criteria ${ }^{\circledR}$ (AGS Beers
Criteria $\left.{ }^{\circledR}\right) .{ }^{52}$ In the present study, all the participants' PIMs were determined in two main categories: PIMs independent of medical condition and PIMs avoided in the older adults due to drug-disease or drug-syndrome interactions.

\section{DDI}

By definition, DDI is a situation in which one substance affects the activity of another drug when both are used simultaneously. ${ }^{53}$ In this study, DDIs were evaluated as minor, moderate, major and contraindicated DDIs, based on severity rating risk in all participants using the Micromedex Drug Interaction Database. ${ }^{54}$ In addition, common potential effects of drug combinations were determined as well.

\section{Contraindicated DDI}

The drug combination is contraindicated for concurrent use. $^{54}$

\section{Major DDI}

The interaction that may be lethal and/or need an additional medical intervention to minimize or prevent some serious detrimental consequences. ${ }^{54}$

\section{Moderate DDI}

The interaction may lead to an aggravation of the patient's clinical status and/or need a change in treatment. ${ }^{54}$

\section{Minor DDI}

The interaction would have limited clinical effects. ${ }^{54}$

\section{Statistical Analysis}

The statistical analyses for this study were performed with the SPSS for Windows Software Package, Version 25 (SPSS Inc., Chicago, Ill., USA). Comparison analyses in terms of demographic characteristics, physical status, comorbidities, degree of cognitive impairment, medication use and prevalence of PP, PIM and DDI between the early period (2009) and the final period (2015-2016) were performed using Pearson's chi-square test or Fisher's exact for categorical variables and Unpaired Student's $t$-test or Mann-Whitney $U$-test for continuous variables. Descriptive analysis of participants' data were presented as percentage, mean (standard deviation or SD) or median (interquartile range or IQR). Logistic regression analysis was performed to explore risk factors associated with exposure to $>1$ criteria of PP, PIM or DDI in each period. A multivariate logistic regression analysis was performed to adjust the factors that could confound the results and to 
identify independent risk factors associated with exposure to $>1$ criteria of PP, PIM or DDI. The multivariate logistic model was adjusted for age, sex, number of comorbidities, short ADL scale, premorbid IADLs scale and significant variables from univariate logistic model to explore independent risk factors in each period. The results were recorded as odd ratios (ORs) and $95 \%$ confidence intervals (CIs). $P$ values were determined as significant at the level of $\mathrm{p}<0.05$.

This study was a secondary retrospective analysis using de-identified data from the interRAI Acute Care (AC) assessment system. Exemption from ethics approval was obtained from Human Research and Metro South Human Research Ethics Committee.

\section{Results}

\section{Study Population}

Five hundred and forty patients were referred for the geriatric consultation services during the study periods. Three hundred and thirty participants aged 65 years or older with cognitive impairment (CPS scores $\geq 2$ ) were included in the present study. The populations of the early (2009) and final period (2015-2016) were 190 and 140, respectively. The mean age was 80.3 (7.6) years, which was not significantly different between the two groups. The baseline characteristics are shown in Table 1. The majority of the participants (54.2\%) were female in the early period whereas over half of the participants $(57.9 \%)$ were male in the final period. Before admission, approximately $90 \%$ of the participants lived in the community, and less than half lived alone. In all, $6.8 \%$ were admitted from residential aged care facilities (RACF) in 2009, but there were none admitted from RACFs between 2015 and 2016. The median length of hospital stay was not significantly different between the two periods [ 35 days (interquartile range (IQR) 22-59 days) in 2009 vs 36 days (IQR 23-54 days) in 2015-2016, $\mathrm{p}=0.957]$. In terms of discharge destination, the number of participants discharged to community was substantially higher in 2009 as compared to $2015-2016$ (51.6\% vs $35 \%)(\mathrm{p}=0.006)$. In both periods, approximately $6 \%$ died in hospital.

In terms of comorbidities, the patients in the later time period had slightly more comorbidities than in the earlier group, as shown in Table 2 . Over $75 \%$ of the total population had $>3$ morbidities. Both groups were more likely to have hypertension $(57.4 \%$ in 2009 vs $54.3 \%$ in $2015-2016)$ and infection (33.2\% in 2009 vs $34.3 \%$ in 2015-2016). It was found that there were significant
Table I Demographic of the Population in 2009 and 2015 to 2016

\begin{tabular}{|c|c|c|c|}
\hline Characteristics & $\begin{array}{l}2009 \\
(n=190), \\
N(\%)\end{array}$ & $\begin{array}{l}20|5-20| 6 \\
(n=\mid 40), \\
N(\%)\end{array}$ & $P$ value \\
\hline $\begin{array}{l}\text { Age in years, mean } \\
\text { (SD) } \\
\leq 75 \text { years } \\
>75 \text { years }\end{array}$ & $\begin{array}{l}80.1(7.9) \\
57(30) \\
133(70)\end{array}$ & $\begin{array}{l}80.4(7.3) \\
38(27.1) \\
102(72.9)\end{array}$ & 0.802 \\
\hline $\begin{array}{l}\text { Sex } \\
\qquad \text { Male } \\
\text { Female }\end{array}$ & $\begin{array}{l}87(45.8) \\
103(54.2)\end{array}$ & $\begin{array}{l}81(57.9) \\
59(42.1)\end{array}$ & 0.03 \\
\hline $\begin{array}{l}\text { Marital status } \\
\text { Single } \\
\text { Married } \\
\text { Widowed } \\
\text { Divorced or separated }\end{array}$ & $\begin{array}{l}18(9.5) \\
68(35.8) \\
80(42.1) \\
24(12.6)\end{array}$ & $\begin{array}{l}13(9.3) \\
45(32.1) \\
44(31.4) \\
38(27.1)\end{array}$ & 0.008 \\
\hline $\begin{array}{l}\text { Living alone } \\
\text { Admission sources } \\
\text { Community } \\
\text { Hospital } \\
\text { RACF }\end{array}$ & $\begin{array}{l}77(40.5) \\
170(89.5) \\
7(3.7) \\
13(6.8)\end{array}$ & $\begin{array}{l}67(47.9) \\
128(91.4) \\
12(8.6) \\
-\end{array}$ & $\begin{array}{l}0.184 \\
0.002\end{array}$ \\
\hline $\begin{array}{l}\text { Length of hospital stay } \\
\text { in days, median (IQR) } \\
\text { Discharge destination } \\
\text { Community } \\
\text { Hospital } \\
\text { RACF } \\
\text { Death }\end{array}$ & $\begin{array}{l}35(22,59) \\
98(51.6) \\
22(11.6) \\
58(30.5) \\
12(6.3)\end{array}$ & $\begin{array}{l}36(23,54) \\
49(35) \\
32(22.9) \\
52(37.1) \\
7(5)\end{array}$ & $\begin{array}{l}0.957 \\
0.006\end{array}$ \\
\hline $\begin{array}{l}\text { Weight (kg), median } \\
\text { (IQR) }\end{array}$ & $64.6(16.8)$ & $65.0(16.6)$ & 0.266 \\
\hline $\begin{array}{l}\text { BMI }\left(\mathrm{kg} / \mathrm{m}^{2}\right), \text { mean } \\
\text { (SD) }\end{array}$ & $23.6(5.7)$ & $23.5(4.9)$ & 0.949 \\
\hline
\end{tabular}

Abbreviations: RACF, residential aged care facilities; kg, kilogram; m, meter; SD, standard deviation; IQR, interquartile range.

differences in the number of patients having dementia, spondylosis, valvular heart disease and psychiatric problems between the two periods $(\mathrm{p}<0.05)$. The most common primary diagnosis were fractures $(22.1 \%)$ in 2009 and falls $(23.6 \%)$ in 2015-2016. In terms of functional status and geriatric syndromes, the participants in the earlier period had a tendency to have greater dependence in basic ADL $(\mathrm{p}=0.001)$ and higher impaired vision $(p=0.004)$ as compared to those in the later period. The majority $(90 \%)$ were likely to have mild to moderate cognitive impairment with CPS scores ranging from 2 to 4 compared with severe cognitive impairment. Finally, it was found that the number of patients with weight loss 
Table 2 Clinical Characteristics of the Population in 2009 and 2015 to 2016

\begin{tabular}{|c|c|c|c|}
\hline Characteristics & $\begin{array}{l}2009 \\
(n=190), \\
N(\%)\end{array}$ & $\begin{array}{l}20|5-20| 6 \\
(n=\mid 40), \\
N(\%)\end{array}$ & $P$ value \\
\hline \multicolumn{4}{|l|}{ Comorbidities } \\
\hline $\begin{array}{l}\text { No. of comorbidities/person, } \\
\text { mean (SD) }\end{array}$ & $4.8(2.1)$ & $5.3(2.2)$ & 0.079 \\
\hline $\begin{array}{l}\text { No. of comorbidities > 3/ } \\
\text { person }\end{array}$ & $146(76.8)$ & $108(77.1)$ & 0.949 \\
\hline Hypertension & $109(57.4)$ & $76(54.3)$ & 0.577 \\
\hline Diabetes mellitus & $41(21.6)$ & $27(19.3)$ & 0.611 \\
\hline Coronary artery disease & $60(31.6)$ & $42(30)$ & 0.759 \\
\hline Valvular heart disease & $18(9.5)$ & $5(3.6)$ & 0.037 \\
\hline Ischemic stroke & $52(27.4)$ & $26(18.6)$ & 0.063 \\
\hline Dementia & $36(18.9)$ & $42(30)$ & 0.020 \\
\hline Malignancy & $46(24.2)$ & $46(32.9)$ & 0.083 \\
\hline Infection & $63(33.2)$ & $48(34.3)$ & 0.830 \\
\hline GERD & $46(24.2)$ & $47(33.6)$ & 0.062 \\
\hline Psychiatric disease & $18(9.5)$ & $24(17.1)$ & 0.039 \\
\hline Spondylosis & $7(3.7)$ & $15(10.7)$ & 0.011 \\
\hline \multicolumn{4}{|l|}{ Primary diagnosis } \\
\hline Fracture & $42(22.1)$ & $12(8.6)$ & 0.005 \\
\hline Fall & $29(15.3)$ & $33(23.6)$ & 0.090 \\
\hline \multicolumn{4}{|l|}{ Geriatric syndrome } \\
\hline Cognitive status at admission ${ }^{\mathrm{a}}$ & & & \\
\hline Mild-moderate impairment (2-4) & $162(85.3)$ & $129(92.1)$ & 0.056 \\
\hline Severe impairment (5-6) & $28(14.7)$ & $11(7.9)$ & \\
\hline $\begin{array}{l}\text { Short } A D L \text { scale at admission, } \\
\text { median (IQR) }\end{array}$ & $7(3,12)$ & $4(1.3,9)$ & 0.001 \\
\hline Premorbid IADLs, mean (SD) ${ }^{c}$ & $25(12,36)$ & $22.5(9.3,34)$ & 0.272 \\
\hline Weight loss ${ }^{d}$ & $27(14.2)$ & $51(36.4)$ & $<0.001$ \\
\hline Urinary incontinence & $122(64.2)$ & $83(59.3)$ & 0.362 \\
\hline Visual problems & $87(45.8)$ & $42(30)$ & 0.004 \\
\hline Auditory problems & $98(51.6)$ & $66(47.1)$ & 0.426 \\
\hline
\end{tabular}

Notes: ${ }^{a}$ Based on the CPS, which ranges from 0 (intact cognition) to 6 (very severe cognitive impairment); cognitively impaired patients were defined as CPS scores $\geq$ 2, corresponding to a mean Mini Mental State Examination score of $<24$ (40). ${ }^{\text {bT }}$ The ADL short-form scale comprises four items (personal hygiene, walking, toilet use and eating); range is $0-16$, with higher scores reflecting greater level of dependency. 'Premorbid IADL scale summarizes the performance on seven IADL items (meal preparation, housework, finances, medication management, phone use, shopping, and transport). The scale has a range from 0 to 42 , with higher scores indicating greater dependence. ${ }^{\mathrm{d}}$ Loss of $\geq 5 \%$ bodyweight in the 30 days before admission or $\geq 10 \%$ in the 180 days before admission.

Abbreviations: $A D L$, activities of daily living; IADL, instrumental ADL; GERD, gastroesophageal reflux disease; SD, standard deviation; IQR, interquartile range.

was substantially higher in the later period as compared to those in the early period $(36.4 \%$ vs. $14.2 \%)(p<0.001)$.

\section{Prescribed Medication Use}

The number of regular prescribed medications ranged from 0 to 20. One patient in each period was prescribed 20 medications. The median number of medications taken was 8 (IQR 5-11) in the early period and 7 (IQR 5-10) in the final period. Table 3 presents the most common prescribed medications categorized by ATC codes. Overall (2009 and 2015-2016), antithrombotic agents were most commonly taken medications $(76.3 \%$ and $79.3 \%$, respectively), followed by laxatives $(46.8 \%$ and $46.4 \%)$ and drugs for acid-related disorders $(51.1 \%$ and $39.3 \%)$. The number of prescribed medications in dermatological and analgesic agents was significantly greater in 2015-2016 compared with $2009, \mathrm{p}=0.035$ and 0.004 , respectively. In contrast, there was a significant decrease of the prescription of drugs for acid-related disorders, drugs use in diabetes and mineral supplements from 2009 to 2015-2016.

\section{PP, PIM and DDI}

The prevalence of PP, PIMs and DDIs was not significantly different between the two periods, as shown in Table 4. Around $77 \%$ of the participants were exposed to $>1$ criteria of PP, PIM or DDI. Over $75 \%$ in both groups consumed five or more prescribed medications. The number of the participants taking at least 1 PIM increased slightly from 97 (51.1\%) in 2009 to 77 $(55.0 \%)$ in $2015-2016(\mathrm{p}=0.478)$. Two patients $(1.1 \%)$ in the early period were on $\geq 4$ PIMs. Overall, of the 1565 regular prescribed drugs in 2009, 204 (13.0\%) were PIMs identified in 190 patients, as shown in Table 5. Of the 1074 regular medications consumed in 2015-2016, 160 (14.9\%) were PIMs identified in 140 patients. In both periods, the commonest prescribed PIM classifications were cardiovascular system drugs and central nervous system (CNS) medications. Antipsychotics and benzodiazepines were the most frequently prescribed PIMs. The combination of medications leading to potential drug-drug interactions are presented in Tables 4 and 6. In both groups, over $75 \%$ were exposed to $\geq 1$ potential DDI. Three patients (2\%) in 2009 and two (1.5\%) in 2015-2016 were exposed to $>15$ potential DDIs. Of all, 781 potential DDIs occurred in 2009. Of these 781, potential DDIs were categorized into four groups according to severity: $1(0.1 \%) \mathrm{DDI}$ as contraindicated DDI, $336(43.0 \%)$ as major, $389(49.8 \%)$ as moderate and $55(7.0 \%)$ as minor, as shown in Table 4. In all, patients were exposed to 416 potential DDIs in 2015-2016. Of these 416, potential DDIs were categorized into four groups according to severity: $2(0.5 \%)$ as contraindicated DDI, 210 $(50.5 \%)$ as major, $194(46.6 \%)$ as moderate and $10(2.4 \%)$ as minor. The drug combination frequently implicated in potential DDI in both periods was the combination of heparin with aspirin, the interactive effect of which increases a risk of bleeding. 
Table 3 Prescribed Medications Use in 2009 and 2015-2016 According to ATC System

\begin{tabular}{|c|c|c|c|c|}
\hline Characteristics & $\begin{array}{l}2009(n=190) \\
N(\%)\end{array}$ & $\begin{array}{l}20|5-20| 6(n=\mid 40) \\
N(\%)\end{array}$ & $\begin{array}{l}\text { Difference in Prevalence, \% } \\
(95 \% \mathrm{Cl})\end{array}$ & $P$ value \\
\hline Total number of medications & $1565(100)$ & $1074(100)$ & & \\
\hline No. of prescribed medications/person, median (IQR) & $8(5,11)$ & $7(5,10)$ & & 0.119 \\
\hline \multicolumn{5}{|l|}{$\begin{array}{l}\text { Prescribed medications according to ATC } \\
\text { classes and codes }\end{array}$} \\
\hline A02 Drugs for acid-related disorders & $97(5 \mathrm{I} . \mathrm{l})$ & $55(39.3)$ & $-11.8(-22.5$ to -1.0$)$ & 0.034 \\
\hline A06 Drugs for constipation & $89(46.8)$ & $65(46.4)$ & $-0.4(-11.3-10.5)$ & 0.941 \\
\hline A10 Drug used in diabetes & $33(17.4)$ & $12(8.6)$ & $-8.8(-15.9$ to -1.7$)$ & 0.021 \\
\hline All Vitamins & $82(43.2)$ & $48(34.3)$ & $-8.9(-19.4-1.7)$ & 0.103 \\
\hline A12 Mineral supplements & $84(44.2)$ & $41(29.3)$ & $-14.9(-25.2$ to -4.6$)$ & 0.006 \\
\hline BOI Antithrombotic agents & $145(76.3)$ & III (79.3) & $2.9(-6.1-12)$ & 0.523 \\
\hline CoI Cardiac therapy & $44(23.2)$ & $25(17.9)$ & $-5.3(-14.0-3.4)$ & 0.242 \\
\hline C02 Antihypertensives & $9(4.7)$ & $8(5.7)$ & $1.0(-3.9-5.9)$ & 0.691 \\
\hline C03 Diuretics & $55(28.9)$ & $31(22.1)$ & $-6.8(-16.2-2.6)$ & 0.164 \\
\hline C07 Beta blocking agents & $59(31.1)$ & $51(36.4)$ & $5.3(-4.9-15.7)$ & 0.306 \\
\hline C08 Calcium channel blockers & $4 \mid(2 \mid .6)$ & $26(18.6)$ & $-3.0(-11.7-5.7)$ & 0.502 \\
\hline C09 Agents acting on the renin-angiotensin system & $72(37.9)$ & $56(40)$ & $2.1(-8.6-12.8)$ & 0.698 \\
\hline CIO Lipid modifying agents & $66(34.7)$ & $48(34.3)$ & $-0.5(-10.8-9.9)$ & 0.932 \\
\hline D Dermatologicals & $7(3.7)$ & $13(9.3)$ & $5.6(0.1-11.1)$ & 0.035 \\
\hline J0I Antibacterial drugs & $46(24.2)$ & $32(22.9)$ & $-1.4(-10.6-7.9)$ & 0.775 \\
\hline N02 Analgesics & $55(28.9)$ & $62(44.3)$ & $15.3(4.9-25.8)$ & 0.004 \\
\hline N03 Antiepileptics & $30(15.8)$ & $14(10)$ & $-5.8(-12.8-1.4)$ & 0.126 \\
\hline N05 Psycholeptics & $48(25.3)$ & $38(27.1)$ & $1.9(-7.7-11.5)$ & 0.701 \\
\hline N05A Antipsychotics & $30(15.8)$ & $30(21.4)$ & $5.6(-2.9-14.2)$ & 0.189 \\
\hline N05B-N05C Anxiolytics, sedatives and hypnotics & $24(12.6)$ & $10(7.1)$ & $-5.5(-11.9-0.9)$ & 0.105 \\
\hline N06 Psychoanaleptics & $44(23.2)$ & $40(28.6)$ & $5.4(-4.2-15.0)$ & 0.265 \\
\hline N06A Antidepressants & $42(22.1)$ & $40(28.6)$ & $6.5(-3.1-16.0)$ & 0.179 \\
\hline N06D Anti-dementia drugs & $3(1.6)$ & $2(1.4)$ & $-0.2(-2.8-2.5)$ & 1.000 \\
\hline
\end{tabular}

Abbreviations: IQR, interquartile range; ATC, anatomical therapeutic chemical.

\section{Risk Factors Associated with Exposure to $>$ I Criteria of PP, PIM or DDI}

According to univariate logistic regression analysis, gender, age, cognitive status and activities of daily living, revealed no significant association with increased exposure to $>1$ criteria of PP, PIM or DDI ( $\mathrm{P}>0.05)$, as shown in Table 7. In 2009, the presence of diabetes diagnosis was significantly associated with a greater risk of exposure to $>1$ criteria of PP, PIM or DDI in univariate analysis $(\mathrm{OR}=4.49$ [1.31-15.38]) and this remained significant $(\mathrm{OR}=4.54$ [1.13-18.25]) after adjustment for age, gender, number of comorbidity, short ADL scale, premorbid IADLs scale in multivariate models. No significant associations were found between specific prescribed medications and increased exposure to $>1$ criteria of PP, PIM or DDI in adjusted models (Table 7).

\section{Discussion}

The current study presented changes in patterns of prescribed medication use and in prevalence and characteristics of PP, PIM and DDI among hospitalized older adults with cognitive impairment. In terms of changes in medication use, common use of antithrombotic agents corresponds with increasing prevalence of chronic heart diseases, ischemic stroke and comorbidities associated with cardiovascular disease such as hypertension, dyslipidemia and diabetes mellitus. ${ }^{55}$ In addition, the introduction and demonstrated effectiveness of antithrombotic agents, following guideline recommendations for treatment and prevention of coronary syndrome and atrial fibrillation have been encouraged, resulting in increased use of antithrombotic medicines in older persons. Moreover, NOACs were approved by the Food and Drug Administration 
Table 4 Prevalence and Comparison of Medication Issues in 2009 and 2015-2016

\begin{tabular}{|c|c|c|c|c|}
\hline Characteristics & $\begin{array}{l}2009(n=190) \\
N(\%)\end{array}$ & $\begin{array}{l}2015-2016(n=140) \\
N(\%)\end{array}$ & $\begin{array}{l}\text { Difference in Prevalence, \% } \\
(95 \% \mathrm{Cl})\end{array}$ & $P$ value \\
\hline $\begin{array}{l}\text { Polypharmacy (PP) } \\
0-4 \text { medications (non-polypharmacy) } \\
5-9 \text { medications (polypharmacy) } \\
\geq 10 \text { medications (excessive } \\
\text { polypharmacy) }\end{array}$ & $\begin{array}{l}33(17.4) \\
86(45.3) \\
71(37.4)\end{array}$ & $\begin{array}{l}30(21.4) \\
71(50.7) \\
39(27.9)\end{array}$ & $\begin{array}{l}4.1(-4.6-12.7) \\
5.5(-5.4-16.4) \\
-9.5(-19.6-0.6)\end{array}$ & 0.184 \\
\hline $\begin{array}{l}\text { Potentially inappropriate medications } \\
\text { (PIMs) } \\
\text { No. of PIM/elderly person, median (IQR) } \\
\text { No PIM } \\
\text { At least I PIM }\end{array}$ & $\begin{array}{l}I(0,1) \\
93(48.9) \\
97(51.1)\end{array}$ & $\begin{array}{l}I(0,1) \\
63(45) \\
77(55)\end{array}$ & $\begin{array}{l}-3.9(-14.8-6.9) \\
3.9(-6.9-14.8)\end{array}$ & $\begin{array}{l}0.907 \\
0.478\end{array}$ \\
\hline $\begin{array}{l}\text { Drug-drug interactions (DDIs) } \\
\text { No. of DDI/ elderly person, median (IQR) } \\
\text { Without DDI } \\
\text { At least I DDI } \\
\text { Total DDIs } \\
\text { Contraindicated DDI } \\
\text { Major DDI } \\
\text { Moderate DDI } \\
\text { Minor DDI }\end{array}$ & $\begin{array}{l}3(1,6) \\
41(21.6) \\
149(78.4) \\
781(100) \\
1(0.1) \\
336(43) \\
389(49.8) \\
55(7)\end{array}$ & $\begin{array}{l}2(1,4) \\
33(23.6) \\
107(76.4) \\
416(100) \\
2(0.5) \\
210(50.5) \\
194(46.6) \\
10(2.4)\end{array}$ & $\begin{array}{l}2.0(-7.2-11.1) \\
-2.0(-11.1-7.2)\end{array}$ & $\begin{array}{l}0.05 \\
0.668\end{array}$ \\
\hline $\begin{array}{l}\text { Exposure to criteria of PP, PIM and } \\
\text { DDI } \\
\text { Exposure to >I criteria of PP, PIM, DDI }\end{array}$ & | 48 (77.9) & $109(77.9)$ & $0.0(-9.1-9.0)$ & 1.000 \\
\hline
\end{tabular}

Abbreviations: IQR, interquartile range; PP, polypharmacy; PIM, potentially inappropriate medication; DDI, drug-drug interaction.

Table 5 Potentially Inappropriate Medications in 2009 and 2015-2016 According to the 2019 Beer Criteria

\begin{tabular}{|c|c|c|c|c|c|}
\hline \multicolumn{3}{|c|}{ PIMs Independence of Medical Conditions } & \multicolumn{3}{|c|}{ PIMs Due to Drug-Disease or Drug-Syndrome Interactions } \\
\hline \multirow[t]{2}{*}{$\begin{array}{l}\text { System/Therapeutic } \\
\text { category/ Drugs }\end{array}$} & $\begin{array}{l}2009(n=204 \\
\text { PIMs) }\end{array}$ & $\begin{array}{l}2015-2016 \\
(n=160 \text { PIMs) }\end{array}$ & \multirow[t]{2}{*}{$\begin{array}{l}\text { System/Therapeutic } \\
\text { category/ Drugs }\end{array}$} & $\begin{array}{l}2009(n=204 \\
\text { PIMs) }\end{array}$ & $\begin{array}{l}2015-2016 \\
(n=160 \text { PIMs })\end{array}$ \\
\hline & $\mathbf{N}(\%)$ & $\mathbf{N}(\%)$ & & $\mathbf{N}(\%)$ & N (\%) \\
\hline Central nervous system & $75(36.8)$ & $63(39.4)$ & Central nervous system & $46(22.5)$ & $46(28.8)$ \\
\hline Cardiovascular system & $30(14.7)$ & $19(11.9)$ & Delirium & $26(12.7)$ & $20(12.6)$ \\
\hline Endocrine & $7(3.4)$ & I (0.6) & $\begin{array}{l}\text { Dementia or cognitive } \\
\text { impairment }\end{array}$ & $20(9.8)$ & $26(16.2)$ \\
\hline \multirow[t]{3}{*}{ Pain medications } & $2(1)$ & $2(1.2)$ & History of falls or fractures & $42(20.6)$ & $26(16.2)$ \\
\hline & & & Gastrointestinal system & I (0.5) & I (0.6) \\
\hline & & & Parkinson disease & $I(0.5)$ & $2(1.2)$ \\
\hline Total & II 4 (55.9) & $85(53.1)$ & Total & $90(44.1)$ & $75(46.9)$ \\
\hline
\end{tabular}

Abbreviation: PIMs, potentially inappropriate medications.

(FDA) for novel oral anticoagulants; therefore, these medications were widely used in clinical practice including among the geriatric population. ${ }^{56}$ An increase in analgesics use from 2009 to 2015-2016 may be related to increase in the number of patients with falls, spondylosis or malignancy including bone metastasis. The patients with these conditions need more prescriptions of analgesic agents. Furthermore, this situation may represent an increasing awareness of under-treatment of pain symptoms as well as adoption of new analgesic agents. ${ }^{57,58}$ Analgesic 
Table 6 Most Common Potential Drug-Drug Interactions and Potential Effects According to Micromedex Drug Interaction Database in 2009 and 2015-2016

\begin{tabular}{|c|c|c|c|}
\hline Drug Combination & Potential Effects & $\begin{array}{l}2009(n=781) \\
N(\%)\end{array}$ & $\begin{array}{l}20|5-20| 6(n=4 \mid 6) \\
N(\%)\end{array}$ \\
\hline Aspirin + Heparin & Increased risk of bleeding & $38(4.9)$ & $24(5.8)$ \\
\hline Aspirin + Furosemide & Reduced diuretic effectiveness and possible nephrotoxicity & $26(3.3)$ & $3(0.7)$ \\
\hline $\begin{array}{l}\text { Polyethylene glycol + } \\
\text { Senna }\end{array}$ & Increased risk of mucosal ulceration or ischemic colitis & $26(3.3)$ & $21(5)$ \\
\hline Aspirin + Calcium & Decreased salicylate effectiveness & $22(2.8)$ & $2(0.5)$ \\
\hline Aspirin + Metformin & Increased risk of hypoglycemia & $13(1.7)$ & $3(0.7)$ \\
\hline Digoxin + Furosemide & Increased risk of digoxin toxicity & $10(1.3)$ & $7(1.7)$ \\
\hline Digoxin + Aspirin & $\begin{array}{l}\text { Increased serum concentration of digoxin; prolonged half-life of } \\
\text { digoxin }\end{array}$ & $8(1.0)$ & $6(1.4)$ \\
\hline
\end{tabular}

Table 7 Logistic Regression Model of Factors Associated with Exposure to > I Criteria of PP, PIM or DDI

\begin{tabular}{|c|c|c|c|c|}
\hline \multirow[t]{2}{*}{ Variables } & \multicolumn{2}{|l|}{2009} & \multicolumn{2}{|l|}{$2015-2016$} \\
\hline & $\begin{array}{l}\text { Unadjusted OR } \\
(95 \% \mathrm{Cl})\end{array}$ & $\begin{array}{l}\text { Adjusted } O R^{a} \\
(95 \% \mathrm{Cl})\end{array}$ & $\begin{array}{l}\text { Unadjusted OR } \\
(95 \% \mathrm{CI})\end{array}$ & $\begin{array}{l}\text { Adjusted } O R^{a} \\
(95 \% \mathrm{Cl})\end{array}$ \\
\hline $\begin{array}{l}\text { Patient characteristics } \\
\text { Age } \\
\text { Female } \\
\text { Short ADL scale } \\
\text { Premorbid IADLs } \\
\text { Number of comorbidities } \\
\text { Diabetes mellitus } \\
\text { Coronary artery disease }\end{array}$ & $\begin{array}{l}0.98(0.93-1.02) \\
1.49(0.74-3.02) \\
1.01(0.95-1.09) \\
1.01(0.98-1.02) \\
1.29(1.09-1.54)^{* *} \\
4.49(1.31-15.38)^{*} \\
1.63(0.74-3.59)\end{array}$ & $4.54(1.13-18.25)^{*}$ & $\begin{array}{l}\text { I.0 }(0.95-1.06) \\
0.83(0.37-1.88) \\
\text { I.02 }(0.94-1.12) \\
\text { I.0I }(0.98-1.04) \\
\text { I.3I }(1.08-1.59)^{* *} \\
\text { I.8I }(0.57-5.68) \\
3.61(1.17-I I .09)^{*}\end{array}$ & \\
\hline $\begin{array}{l}\text { Medications characteristics } \\
\text { A02 Drugs for acid-related disorders } \\
\text { A06 Drugs for constipation } \\
\text { A10 Drug used in diabetes } \\
\text { A12 Mineral supplements } \\
\text { B0I Antithrombotic agents } \\
\text { C01 Cardiac therapy } \\
\text { C02 Antihypertensives } \\
\text { C03 Diuretics } \\
\text { C09 Agents acting on the renin- } \\
\text { angiotensin system } \\
\text { C10 Lipid modifying agents } \\
\text { N06 Psychoanaleptics }\end{array}$ & $\begin{array}{l}4.56(2.09-9.98)^{* *} \\
1.58(0.78-3.19) \\
5.29(1.21-23.15)^{*} \\
2.74(1.29-5.86)^{* *} \\
2.52(1.20-5.31)^{*} \\
16.79(2.24-126)^{* *} \\
1.84(0.92-3.68) \\
2.97(1.17-7.52)^{*} \\
1.13(0.55-2.30) \\
2.74(1.19-6.33)^{*} \\
3.52(1.18-10.48)^{*}\end{array}$ & $7.89(0.99-62.34)$ & $\begin{array}{l}2.69(1.07-6.79)^{*} \\
6.37(2.28-17.81)^{* *} \\
3.37(0.42-27.16) \\
2.56(0.91-7.23) \\
4.19(1.73-10.21)^{* *} \\
8.47(1.09-65.35)^{*} \\
4.19(1.80-9.71)^{* *} \\
11.39(1.49-87.28)^{*} \\
6.16(2.02-18.79)^{* *} \\
2.07(0.82-5.22) \\
2.46(0.87-6.95)\end{array}$ & $\begin{array}{l}3.21(0.98-10.5) \\
0.84(0.82-56.9)\end{array}$ \\
\hline
\end{tabular}

Notes: ${ }^{2}$ Adjusted for age, sex, number of comorbidities, short $A D L$ scale, premorbid IADLs and significant variable from unadjusted model, $* P<0.05$, $* * P<0.0$ I Abbreviations: $A D L$, activities of daily living; IADL, instrumental $A D L$; OR, odds ratio; $\mathrm{Cl}$, confidence interval.

agents as over-the-counter (OTC) pain relievers have been increasingly prescribed over this period of time. Although analgesics use has substantially increased in clinical practice, only two patients were prescribed non-steroidal antiinflammatory drugs which should be avoided as chronic use owing to an increased risk of peptic ulcer disease and gastrointestinal bleeding. ${ }^{52}$ In contrast, a great reduction in prescribing of drugs for acid-related disorder including proton pump inhibitors (PPIs) might be associated with improved recommendation guidelines for PPI prescribing in the last decade. Implementation of updated treatment guidelines may have contributed to decreased prescription of PPIs ${ }^{29}$ in order to reduce risk of unintended adverse consequences such as $C$. difficile infection, osteoporosis 
and hip fractures in long-term use. ${ }^{59-62}$ The majority of the participants were exposed to PP (75\%), PIM (50\%) or DDI (75\%). Despite remaining high, the number of patients exposed to $>1$ PP, PIM or DDI has not significantly increased over the time period of the study. This may reflect new developed criteria that address many aspects of medication prescribing in older patients such as the Beers and the STOPP/START criteria, leading to increased awareness of medication use.

As expected, PP was prevalent in a high proportion $(>75 \%)$ of the study population, which can be explained from higher multi-comorbidities or chronic diseases and changes of clinical practice guidelines for treatment of several chronic diseases. ${ }^{63}$

The majority of older patients with cognitive impairment admitted in the acute care setting were exposed to $\geq 1$ PIMs, which corresponds to a study of von-Ranteln Kruse. ${ }^{43}$ However, the variability in prevalence of PIM depends on the population studies and the measure tools such as the Beers Criteria, the STOPP/START criteria, PRISCUS list, Laroche list. ${ }^{19,52,64,65}$ With regard to PIMs, antipsychotics and benzodiazepines are widely prescribed to treat neuropsychiatric problems in the older population with cognitive impairment or dementia ${ }^{66}$ although these medications should not be used as first-line treatment. This is not beyond expectation that antipsychotic agents and benzodiazepines are common PIMs for cognitively impaired older people, ${ }^{43}$ leading to increased exposure to PIMs and negative health outcomes. ${ }^{67,68}$

The higher prevalence of specific diseases in older patients with cognitive impairment could guide physicians to predict associated DRPs with those diseases. ${ }^{69}$ For example, with a greater prevalence of cardiovascular and neurological diseases such as hypertension, ischemic heart disease and ischemic stroke, there are greater potential DDIs related to cardiovascular and neurological system medications including the combination of heparin with aspirin. In terms of DDI, most identified drug-paired interactions have been potentially severe. Therefore, combination drug use should be carefully considered and closely monitored.

According to univariate logistic regression analysis, gender, age, cognitive status and activities of daily living did not have an influence on the increase of exposure to PP, PIM and DDI, which contrasts with the results of previous studies..$^{70,71}$ The result of the multivariate regression analysis is consistent with previous studies in that the number of medications taken by a patient is an important risk factor for the occurrence of DRPs. ${ }^{70,72,73}$ Additionally, in 2009, a diagnosis of diabetes mellitus was shown to be a risk for exposure to PP and DRPs including PIM and DDI. Older people with diabetes often have increased number of co-morbidities including stroke, chronic heart disease and hypertension and therefore, a higher risk for PP, PIM and DDI. In 2015-2016, the number of older patients with diabetes significantly decreased which may have resulted from implementation of updated diabetes prevention, ${ }^{74}$ resulting in the decrease of the use of hypoglycemic drugs. Furthermore, new safe hypoglycemic drugs such as sodium-glucose transport protein 2 (SGLT2) inhibitor were introduced and widely used in clinical practice. ${ }^{22}$

Thus, the strategies of regular medication reviews with medication reconciliation to reduce inappropriate medication prescribing may assist physicians or pharmacists to address PP and DRPs. ${ }^{75}$

\section{The Strengths and Limitations}

To the best of our knowledge, no previous study has reported trends in prescribed medication use and changes in prevalence and characteristics of three criteria of PP, PIM and DDI among older hospitalized patients with cognitive impairment over a period of five years. Furthermore, the strength of this study includes the data from comprehensive geriatric assessment using the interRAI Acute Care (AC) assessment system, which has been a standard tool for use in the acute setting.

However, many limitations have to be taken into account. First, the study was conducted only in older people referred for geriatric consultation services in one tertiary hospital during a specific period of time. In addition, only those with cognitive impairment (61\% of referrals) were included in the study, so that the results may not be generalizable to all older inpatients. Second, according to the cross-sectional study design, the temporal relationship of association and outcomes could not be assumed. Third, indication and duration of treatments during admission as well as laboratory results were not recorded and considered, resulting in underestimated PIMs. Fourth, in our study, all medications were recorded at the time of referral for geriatric consultation and were evaluated in terms of pharmacological issues and drug-related problems; nevertheless, some medication regimens which change during admission may have effects on study results. Fifth, this study failed to address other DRPs such as ADRs although these problems often occur among the elderly with cognitive impairment. ${ }^{76}$ Furthermore, all drug interactions were considered only as single pairwise drug combinations, not accounting for 
interactions from three or more drug combinations. Finally, unmeasured or residual confounding factors may remain although multivariate logistic regression analysis was performed to adjust for multiple variables.

\section{Conclusions}

Significant changes in patterns of use of many prescribed medications in older hospitalized patients with cognitive impairment were found over the five years. In addition, the present study confirms that the majority of older adults with cognitive impairment admitted in an acute care setting are prone to PP, PIM and DDI. Moreover, especially in this vulnerable population group, medication reviews to optimize medication prescribing including withdrawing medications as well as considering benefits and risks of medication use are necessary in order to address PP and DRPs.

\section{Acknowledgments}

The authors would like to express our gratitude to Professor Ruth Hubbard, Centre for Health Services Research, Faculty of Medicine, The University of Queensland, for providing valuable advice and comments. The authors would like to thank all trained nurse assessors for gathering comprehensive data in interRAI Acute Care (AC) assessment system database.

\section{Author Contributions}

All authors contributed to data analysis, drafting or revising the article, gave final approval of the version to be published, and agree to be accountable for all aspects of the work.

\section{Funding}

The authors received no financial support for the research.

\section{Disclosure}

The authors report no conflicts of interest in this work.

\section{References}

1. World Health Organization. World Report on Ageing and Health. Geneva: World Health Organization; 2015. Available from http:// www.who.int/ageing/events/world-report-2015-launch. Accessed September 12, 2019.

2. Population projections australia, 2017 to 2066, catalogue no. 3222.0, ABS. Canberra: australian bureau of statistics (ABS); 2018. Available from: https://www.abs.gov.au/3222.0MediaRelease 12017 (base)2066. Accessed september 12, 2019..
3. Andrew MK, Rockwood K. Making our health and care systems fit for an ageing population: considerations for Canada. Can Geriatr J. 2014;17(4):133-135. doi:10.5770/cgj.17.163

4. Cornwell J, Levenson R, Sonola L, Poteliakhoff E. Continuity of care for older hospital patients: a call for action; 2012. Available from: http://www.kingsfund.org.uk/publications/continuity-care-olderhospitalpatients. Accessed September 12, 2019..

5. Pedersen MK, Meyer G, Uhrenfeldt L. Risk factors for acute care hospital readmission in older persons in western countries: a systematic review. JBI Database System Rev Implement Rep. 2017;15(2):454-485. doi:10.11124/JBISRIR-2016-003267

6. Li CL, Chu SJ, Sheu JT, Huang LY. Impact of physical activity on hospitalization in older adults: a nationwide cohort from Taiwan. Arch Gerontol Geriatr. 2011;53(2):141-145. doi:10.1016/j. archger.2010.09.014

7. Albert SM, Colombi A, Hanlon J. Potentially inappropriate medications and risk of hospitalization in retirees: analysis of a US retiree health claims database. Drugs Aging. 2010;27(5):407-415. doi:10.2165/11315990-000000000-00000

8. Reynish EL, Hapca SM, De Souza N, Cvoro V, Donnan PT, Guthrie B. Epidemiology and outcomes of people with dementia, delirium, and unspecified cognitive impairment in the general hospital: prospective cohort study of 10,014 admissions. BMC Med. 2017;15(1):140. doi:10.1186/s12916-017-0899-0

9. Wilson RS, Hebert LE, Scherr PA, Dong X, Leurgens SE, Evans DA. Cognitive decline after hospitalization in a community population of older persons. Neurology. 2012;78(13):950-956. doi:10.1212/ WNL.0b013e31824d5894

10. Marcantonio ER. Delirium in hospitalized older adults. $N$ Eng J Med. 2017;377(15):1456-1466. doi:10.1056/NEJMcp1605501

11. Leto L, Feola M. Cognitive impairment in heart failure patients. J Geriatr Cardiol. 2014;11(4):316-328. doi:10.11909/j.issn.16715411.2014.04.007

12. Morris C, Mitchell JW, Moorey H, Younan HC, Tadros G, Turner AM. Memory, attention, and fluency deficits in COPD may be a specific form of cognitive impairment. ERJ Open Res. 2019;5 (2):00229-2018. doi:10.1183/23120541.00229-2018

13. Fogg C, Griffiths P, Meredith P, Bridges J. Hospital outcomes of older people with cognitive impairment: an integrative review. Int $J$ Geriatr Psychiatry. 2018;33(9):1177-1197. doi:10.1002/ gps.4919

14. Patterson SM, Hughes C, Kerse N, Cardwell CR, Bradley MC. Interventions to improve the appropriate use of polypharmacy for older people. Cochrane Database Syst Rev. 2012;5:CD008165.

15. Clague F, Mercer SW, McLean G, Reynish E, Guthrie B. Comorbidity and polypharmacy in people with dementia: insights from a large, population-based cross-sectional analysis of primary care data. Age Ageing. 2017;46(1):33-39. doi:10.1093/ageing/afw176

16. Hubbard RE, Peel NM, Scott IA, et al. Polypharmacy among inpatients aged 70 years or older in Australia. Med J Aust. 2015;202 (7):373-377. doi:10.5694/mja13.00172

17. Campanelli CM. American Geriatrics Society 2012 Beers Criteria Update Expert Panel. American Geriatrics Society updated Beers Criteria for potentially inappropriate medication use in older adults. $J$ Am Geriatr Soc. 2012;60(4):616-631. doi:10.1111/j.15325415.2012.03923.x

18. Fick DM Semla TP Beizer J, et alBy the 2019 American geriatrics society beers criteria update expert panel. American geriatrics society 2015 updated beers criteria for potentially inappropriate medication use in older adults. J Am Geriatr Soc. 2015;63(11):2227-2246. doi: $10.1111 /$ jgs. 13702

19. Gallagher P, Ryan C, Byrne S, Kennedy J, O'Mahony D. STOPP (screening tool of older person's prescriptions) and START (screening tool to alert doctors to right treatment). Consensus validation. Int J Clin Pharmacol Ther. 2008;46(2):72-83. doi:10.5414/CPP46072 
20. Sönnerstam E, Sjölander M, Gustafsson M. An evaluation of the prevalence of potentially inappropriate medications in older people with cognitive impairment living in Northern Sweden using the EU (7)-PIM list. Eur J Clin Pharmacol. 2017;73(6):735-742. doi:10.1007/s00228-017-2218-2

21. Bajcar JM, Wang L, Moineddin R, Nie JX, Tracy CS, Upshur REG. From pharmaco-therapy to pharmaco-prevention: trends in prescribing to older adults in Ontario, Canada, 1997-2006. BMC Fam Pract. 2010;11(1):75. doi:10.1186/1471-2296-11-75

22. Jay S, Babak BB, Sarah A. Empagliflozin in the treatment of type 2 diabetes: evidence to date. Drug Des Devel Ther. 2015;9:5793-5803. doi:10.2147/DDDT.S69926

23. Gao L, Maidment I, Matthews FE, Robinson L, Brayne C. Medication usage change in older people $(65+)$ in England over 20 years: findings from CFAS I and CFAS II. Age Ageing. 2018;47 (2):220-225. doi:10.1093/ageing/afx158

24. Fried TR, Tinetti ME, Iannone L. Primary care clinicians' experiences with treatment decision making for older persons with multiple conditions. Arch Intern Med. 2011;171(1):75-80. doi:10.1001/ archinternmed.2011.424

25. Oktora MP, Denig P, Bos JHJ, Schuiling-Veninga CCM, Hak E. Trends in polypharmacy and dispensed drugs among adults in the Netherlands as compared to the United States. PLoS One. 2019;14 (3):e0214240. doi:10.1371/journal.pone.0214240

26. Charlesworth CJ, Smit E, Lee DS, Alramadhan F, Odden MC. Polypharmacy among adults aged 65 years and older in the United States: 1988-2010. J Gerontol a Biol Sci Med Sci. 2015;70 (8):989-995. doi:10.1093/gerona/glv013

27. Farrell B, Pottie K, Thompson W, et al. Deprescribing proton pump inhibitors: evidence-based clinical practice guideline. Can Fam Physician. 2017;63(5):354-364.

28. Gnjidic D, Hilmer SN, Blyth FM, et al. Polypharmacy cutoff and outcomes: five or more medicines were used to identify community-dwelling older men at risk of different adverse outcomes. J Clin Epidemiol. 2012;65(9):989-995. doi:10.1016/j. jclinepi.2012.02.018

29. Maher RL Jr, Hanlon JT, Hajjar ER. Clinical consequences of polypharmacy in elderly. Expert Opin Drug Saf. 2014;13(1):57-65. doi:10.1517/14740338.2013.827660

30. Rodrigues MC, Oliveira C. Drug-drug interactions and adverse drug reactions in polypharmacy among older adults: an integrative review. Rev Lat Am Enfermagem. 2016;24:e2800. doi:10.1590/15188345.1316.2800

31. Wastesson JW, Morin L, Tan ECK, Johnell K. An update on the clinical consequences of polypharmacy in older adults: a narrative review. Expert Opin Drug Saf. 2018;17(12):1185-1196. doi:10.1080/ 14740338.2018.1546841

32. Moore AR, O'Keeffe ST. Drug-induced cognitive impairment in the elderly. Drugs Aging. 1999;15(1):15-28. doi:10.2165/00002512199915010-00002

33. Reeve E, Trenaman SC, Rockwood K, Hilmer SN. Pharmacokinetic and pharmacodynamic alterations in older people with dementia. Expert Opin Drug Metab Toxicol. 2017;13(6):651-668. doi:10.1080/17425255.2017.1325873

34. Mangoni AA, Jackson SH. Age-related changes in pharmacokinetics and pharmacodynamics: basic principles and practical applications. Br J of Clin Pharmacol. 2004;57(1):6-14. doi:10.1046/j.13652125.2003.02007.x

35. Lau DT, Kasper JD, Potter DE, Lyles A, Bennett RG. Hospitalization and death associated with potentially inappropriate medication prescriptions among elderly nursing home residents. Arch Intern Med. 2005;165(1):68-74. doi:10.1001/archinte.165.1.68

36. Cahir C, Fahey T, Teeling M, Teljeur C, Feely J, Bennett K. Potentially inappropriate prescribing and cost outcomes for older people: a national population study. Br J Clin Pharmacol. 2010;69 (5):543-552. doi:10.1111/j.1365-2125.2010.03628.x
37. Chen CC, Cheng SH. Potentially inappropriate medication and health care outcomes: an instrumental variable approach. Health Serv Res. 2016;51(4):1670-1691. doi:10.1111/1475-6773.12417

38. Poudel A, Peel NM, Nissen L, Mitchell C, Gray LC, Hubbard RE. Potentially inappropriate prescribing in older patients discharged from acute care hospitals to residential aged care facilities. Ann Pharmacother. 2014;48(11):1425-1433. doi:10.1177/ 1060028014548568

39. Widagdo IS, Nyfort-Hansen K, Kowalski SR. Prevalence of potentially inappropriate medication use in elderly hospitalized patients. J Pharm Pract Res. 2011;41(2):122-125. doi:10.1002/j.20552335.2011.tb00678.x

40. Wahab MS, Nyfort-Hansen K, Kowalski SR. Inappropriate prescribing in hospitalised Australian elderly as determined by the STOPP criteria. Int J Clin Pharm. 2012;34(6):855-862. doi:10.1007/s11096012-9681-8

41. Basger BJ, Chen TF, Moles RJ. Application of a prescribing indicators tool to assist in identifying drug-related problems in a cohort of older Australians. Int J Pharm Pract. 2012;20(3):172-182. doi:10.1111/j.2042-7174.2011.00177.x

42. Redston MR, Hilmer SN, McLachlan AJ, Clough AJ, Gnjidic D. Prevalence of potentially inappropriate medication use in older inpatients with and without cognitive impairment: a systematic review. J Alzheimers Dis. 2018;61(4):1639-1652. doi:10.3233/JAD-170842

43. von Renteln-kruse W, Neumann L, Klugmann B, et al. Geriatric patients with cognitive impairment: patient characteristics and treatment results on a specialized ward. Dtsch Arztebl Int. 2015;11297:103-112.

44. Gray LC, Bernabei R, Berg K, et al. Standardizing assessment of elderly people in acute care: the interRAI Acute Care instrument. $J$ Am Geriatr Soc. 2008;56(3):536-541. doi:10.1111/j.15325415.2007.01590.x

45. Lakhan P, Jones M, Wilson A, Courtney M, Hirdes J, Gray LC. A prospective cohort study of geriatric syndromes among older medical patients admitted to acute care hospitals. J Am Geriatr Soc. 2011;59(11):2001-2008. doi:10.1111/j.1532-5415.2011.03663.x

46. Travers C, Byrne GJ, Pachana NA, Klein K, Gray L. Validation of the interRAI Cognitive Performance Scale against independent clinical diagnosis and the Mini-Mental State Examination in older hospitalized patients. $J$ Nutr Health Aging. 2013;17(5):435-439. doi:10.1007/s12603-012-0439-8

47. Gray L, Ariño-Blasco S, Berg K, et al. interRAI Acute Care (AC) Assessment Form and User's Manual. Washington, DC: interRAI; 2010.

48. Gray LC, Berg K, Fries BE, et al. Sharing clinical information across care settings: the birth of an integrated assessment system. $B M C$ Health Serv Res. 2009;9(1):71. doi:10.1186/1472-6963-9-71

49. WHO Collaborating Centre for Drug Statistics Methodology. Guidelines for ATC classification and DDD assignment; 2019. Oslo. Available from: http://www.whocc.no/filearchive/publications/ 2019_guidelines_web.pdf. Accessed September 5, 2019.

50. Onder G, Liperoti R, Fialova D, et al. Polypharmacy in nursing home in Europe: results from the SHELTER study. J Gerontol a Biol Sci Med Sci. 2012;67(6):698-704. doi:10.1093/gerona/glr233

51. Beers MH. Explicit criteria for determining potentially inappropriate medication use by the elderly. An update. Arch Intern Med. 1997;157 (14):1531-1536. doi:10.1001/archinte.1997.00440350031003

52. Fick DM Semla TP Steinman M, et al. By the 2019 American geriatrics society beers criteria update expert panel. American geriatrics society 2019 updated AGS beers criteria for potentially inappropriate medication use in older adults. J Am Geriatr Soc. 2019;67 (4):674-694. doi:10.1111/jgs.15767

53. Triplitt C. Drug interactions of medications commonly used in diabetes. Diabetes Spectrum. 2006;19(4):202-211. doi:10.2337/ diaspect.19.4.202 
54. Reuters T. Micromedex ${ }^{\circledR}$ HealthCare Series (Internet Database) Version 2.0. Greenwood Village, Colorado: Thomson Healthcare Inc; 2013. Available from http://www.micromedexsolutions.com. Accessed September 5, 2019.

55. Craftman AG, Johnell K, Fastbom J, Westerbotn M, von Strauss E. Time trends in 20 years of medication use in older adults: findings from three elderly cohorts in Stockholm, Sweden. Arch Gerontol Geriatr. 2016;63:28-35. doi:10.1016/j.archger.2015.11.010

56. How CH. Novel oral anticoagulants for atrial fibrillation. Singapore Med J. 2015;56(12):657-658. doi:10.11622/smedj.2015184

57. Haasum Y, Fastbom J, Fratiglioni L, Kareholt I, Johnell K. Pain treatment in elderly persons with and without dementia: a population-based study of institutionalized and home-dwelling elderly. Drugs Aging. 2011;28(4):283-293. doi:10.2165/11587040000000000-00000

58. Franchi C, Tettamanti M, Pasina L, et al. Changes in drug prescribing to Italian community-dwelling elderly people: the EPIFARM-Elderly Project 2000-2010. Eur J Clin Pharmacol. 2014;70(4):437-443. doi:10.1007/s00228-013-1621-6

59. Trifan A, Stanciu C, Girleanu I, et al. Proton pump inhibitors therapy and risk of Clostridium difficile infection: systematic review and meta-analysis. World J Gastroenterol. 2017;23(35):6500-6515. doi:10.3748/wjg.v23.i35.6500

60. Thong BKS, Ima-Nirwana S, Chin KY. Proton pump inhibitors and fracture risk: a review of current evidence and mechanisms involved. Int J Environ Res Public Health. 2019;16(9):pii:E1571. doi:10.3390/ ijerph16091571

61. Othman F, Card TR, Crooks CJ. Proton pump inhibitor prescribing patterns in the UK: a primary care database study. Pharmacoepidemiol Drug Saf. 2016;25(9):1079-1087. doi:10.1002/ pds.4043

62. Maes ML, Fixen DR, Linnebur SA. Adverse effects of proton-pump inhibitor use in older adults: a review of the evidence. Ther Adv Drug Saf. 2017;8(9):273-297. doi:10.1177/2042098617715381

63. Nobili A, Marengoni A, Tettamanti M, et al. Association between clusters of diseases and polypharmacy in hospitalized elderly patients: results from the REPOSI study. Eur J Intern Med. 2011;22 (6):597-602. doi:10.1016/j.ejim.2011.08.029

64. Holt S, Schmiedl S, Thürmann PA. Potentially inappropriate medications in the elderly: the PRISCUS list. Dtsch Arztebl Int. 2010;107 (31-32):543-551. doi:10.3238/arztebl.2010.0543

65. Laroche ML, Charmes JP, Merle L. Potentially inappropriate medications in the elderly: a French consensus panel list. Eur J Clin Pharmacol. 2007;63(8):725-731. doi:10.1007/s00228-007-0324-2
66. Cerejeira J, Lagarto L, Mukaetova-Ladinska EB. Behavioral and psychological symptoms of dementia. Front Neurol. 2012;3:73. doi:10.3389/fneur.2012.00073

67. Gustafsson M, Karlsson S, Lovheim H. Inappropriate long-term use of antipsychotic drugs is common among people with dementia living in specialized care units. BMC Pharmacol Toxicol. 2013;14(1):10. doi:10.1186/2050-6511-14-10

68. Park H, Satoh H, Miki A, Urushihara H, Sawada Y. Medications associated with falls in older people: systematic review of publications from a recent 5-year period. Eur J Clin Pharmacol. 2015;71 (12):1429-1440. doi:10.1007/s00228-015-1955-3

69. Raut A, Vohra F, Surve R, Pawar A. A study of prescribing pattern, comorbidities, and cost analysis in elderly hospitalized patients in Pune. Chrismed J Health Res. 2016;3(3):191-196. doi:10.4103/23483334.183739

70. Wucherer D, Thyrian JR, Eichler T, et al. Drug-related problems in community-dwelling primary care patients screened positive for dementia. Int Psychogeriatr. 2017;29(11):1857-1868. doi:10.1017/ S1041610217001442

71. Wucherer D, Eichler T, Hertel J, et al. Potentially inappropriate medication in community-dwelling primary care patients who were screened positive for dementia. $J$ Alzheimers Dis. 2017;55 (2):691-701. doi:10.3233/JAD-160581

72. Kaufmann CP, Stampfli D, Hersberger KE, Lampert ML. Determination of risk factors for drug-related problems: a multidisciplinary triangulation process. BMJ Open. 2015;5(3): e006376. doi:10.1136/bmjopen-2014-006376

73. Lau DT, Mercaldo ND, Harris AT, Trittschuh E, Shega J, Weintraub S. Polypharmacy and potentially inappropriate medication use among community-dwelling elders with dementia. Alzheimer Dis Assoc Disord 2010;24(1):56-63 doi:10.1097/ WAD.0b013e31819d6ec9

74. Shi BY. The importance and strategy of diabetes prevention. Chronic Dis Transl Med. 2016;2(4):204-207. doi:10.1016/j.cdtm.2016.11.013

75. Harrison SL, Kouladjian O’Donnell L, Bradley CE, et al. Associations between the drug burden index, potentially inappropriate medications and quality of life in residential aged care. Drugs Aging. 2018;35(1):83-91. doi:10.1007/s40266-017-0513-3

76. Kanagaratnam L, Dramé $M$, Trenque T, et al. Adverse drug reactions in elderly patients with cognitive disorders: a systematic review. Maturitas. 2016;85:56-63. doi:10.1016/j.maturitas.2015.12.013
Clinical Interventions in Aging

\section{Publish your work in this journal}

Clinical Interventions in Aging is an international, peer-reviewed journal focusing on evidence-based reports on the value or lack thereof of treatments intended to prevent or delay the onset of maladaptive correlates of aging in human beings. This journal is indexed on PubMed Central, MedLine, CAS, Scopus and the Elsevier
Bibliographic databases. The manuscript management system is completely online and includes a very quick and fair peer-review system, which is all easy to use. Visit http://www.dovepress.com/ testimonials.php to read real quotes from published authors. 